\title{
Aplicação de nitrogênio e inoculação com rizóbio em feijoeiro cultivado após milho consorciado com braquiária
}

\author{
Emerson de Freitas Cordova de Souza(1), Rogério Peres Soratto(1) e Felipe Augusto Pagani(1)
} (1)Universidade Estadual Paulista, Faculdade de Ciências Agronômicas, Departamento de Produção Vegetal, Campus de Botucatu,
Caixa Postal 237, CEP 18603-970 Botucatu, SP. E-mail: emerson.cordova@hotmail.com, soratto@fca.unesp.br, fapagani@fca.unesp.br

Resumo - O objetivo deste trabalho foi avaliar o efeito de doses de nitrogênio (N) e de inoculação de Rhizobium tropici em feijoeiro cultivado no sistema plantio direto, em sucessão ao milho safrinha consorciado com Urochloa brizantha (Syn. Brachiaria bryzantha) ou Urochloa ruziziensis (Syn. Brachiaria ruziziensis). Dois experimentos foram conduzidos, durante dois anos agrícolas, em Latossolo Vermelho distroférrico. Utilizouse o delineamento de blocos ao acaso, em parcelas subdivididas, com quatro repetições. As parcelas foram constituídas pela inoculação ou não de $R$. tropici nas sementes, e as subparcelas por quatro doses de $\mathrm{N}(0,35$, 70 e $140 \mathrm{~kg} \mathrm{ha}^{-1}$ ). Foram feitas avaliações quanto ao número de nódulos por planta, matéria seca de nódulos, teor de $\mathrm{N}$ na folha, matéria seca da parte aérea, $\mathrm{N}$ acumulado na parte aérea, número de vagens por planta e produtividade de grãos. As variáveis avaliadas, em geral, não foram influenciadas pela inoculação de $R$. tropici. $\mathrm{O}$ acréscimo das doses de $\mathrm{N}$ diminuiu a nodulação e aumentou a produção de matéria seca, o teor e o acúmulo de $\mathrm{N}$ da parte aérea do feijoeiro. A produtividade de grãos do feijoeiro foi pouco influenciada pela adubação nitrogenada.

Termos para indexação: Brachiaria, Phaseolus vulgaris, Rhizobium tropici, Urochloa brizantha, Urochloa ruziziensis, plantio direto.

\section{Nitrogen fertilization and rhizobium inoculation in common bean cultivated after corn intercropped with palisade grass}

\begin{abstract}
The objective of this work was to evaluate the effect of nitrogen (N) doses and Rhizobium tropici inoculation on common bean grown under no-tillage system, after second-crop winter corn intercropped with Urochloa brizantha (Syn. Brachiaria bryzantha) or Urochloa ruziziensis (Syn. Brachiaria ruziziensis). Two experiments were performed during two agricultural years, on a dystroferric Haplorthox. A randomized block design was used in split plots, with four replicates. The plots were constituted of absence or presence of seed inoculation with $R$. tropici, and the subplots were constituted of four $\mathrm{N}$ doses $\left(0,35,70\right.$, and $\left.140 \mathrm{~kg} \mathrm{ha}^{-1}\right)$. Evaluations were made for the number of nodules per plant, nodule dry matter, N-leaf content, shoot dry matter, shoot-accumulated N, number of pods per plant, and grain yield. The evaluated variables were not affected by seed inoculation with $R$. tropici. Increasing doses of $\mathrm{N}$ fertilization decreased nodulation, and increased dry matter yield, $\mathrm{N}$ content and $\mathrm{N}$ accumulation of common bean aerial parts. Common bean grain yield was little influenced by $\mathrm{N}$ fertilization.

Index terms: Brachiaria, Phaseolus vulgaris, Rhizobium tropici, Urochloa brizantha, Urochloa ruziziensis, no-tillage.
\end{abstract}

\section{Introdução}

O nitrogênio $(\mathrm{N})$ é um dos elementos mais limitantes ao crescimento do feijoeiro (Phaseolus vulgaris L.), e muitos trabalhos demonstram que há resposta dessa cultura à aplicação de fertilizantes nitrogenados (Santos et al., 2003; Silveira et al., 2005; Raposeiras et al., 2006; Soratto et al., 2006; Pelegrin et al., 2009; Valadão et al., 2009; Kaneko et al., 2010). Contudo, o adubo nitrogenado tem alto custo energético para sua obtenção e o seu manejo representa uma das principais dificuldades da cultura do feijão (Santos et al., 2003).

Em condições ambientais adequadas, o $\mathrm{N}_{2}$ atmosférico, fixado por meio da simbiose com bactérias do gênero Rhizobium, pode atender parte das necessidades do feijoeiro (Martínez-Romero et al., 1991; Soares et al., 2006; Pelegrin et al., 2009; Valadão et al., 2009). Entretanto, os fatores relacionados, principalmente às condições do solo, frequentemente 
limitam todas as etapas do processo de infecção das raízes, formação de nódulos e assimilação do $\mathrm{N}$ pela planta (Martínez-Romero et al., 1991; Vieira et al., 2005; Silva et al., 2009). Assim, na maioria das vezes, a adubação nitrogenada deve ser complementada, para que se obtenha elevada produtividade de grãos (Raposeiras et al., 2006; Pelegrin et al., 2009; Kaneko et al., 2010).

O sistema plantio direto (SPD), associado ao uso de plantas que proporcionam grande acúmulo de palhada sobre o solo, é uma alternativa eficiente para o controle da erosão, pois favorece a reciclagem de nutrientes, a agregação do solo, o armazenamento da água e a manutenção da matéria orgânica do solo, com efeitos positivos sobre a fertilidade (Boer et al., 2007; Crusciol et al., 2009). Porém, a maior limitação para o SPD, na maior parte do Estado de São Paulo e no Brasil central, é a baixa produção de palhada nos períodos outono/inverno e inverno/primavera, em razão das condições climáticas desfavoráveis, notadamente a baixa disponibilidade hídrica (Kluthcouski \& Stone, 2003; Crusciol et al., 2009).

O cultivo consorciado de culturas como o milho safrinha, semeadas simultaneamente com plantas forrageiras, como as espécies de braquiária, pode manter boa cobertura do solo para o SPD (Ceccon et al., 2010). Além disso, técnicas como utilização de insumos, manejo adequado de adubação e inclusão de gramíneas forrageiras, têm permitido a obtenção de produtividade de feijão bem acima da média nacional (Kluthcouski \& Stone, 2003; Silveira et al., 2005).

As melhores condições edáficas proporcionadas pelo SPD, com adequada cobertura vegetal, beneficiam o desenvolvimento de microrganismos (Barroti \& Nahas, 2000; Silva et al., 2007), o que poderia favorecer a fixação biológica de N. Contudo, são praticamente inexistentes na literatura informações sobre o efeito de culturas anteriores, especialmente as de espécies de braquiária e da resposta do feijoeiro à inoculação das sementes com Rhizobium tropici e a adubação nitrogenada.

O objetivo deste trabalho foi avaliar o efeito de doses de $\mathrm{N}$ e da inoculação com $R$. tropici em feijoeiro cultivado em SPD, em sucessão ao milho safrinha consorciado com Urochloa brizantha (Syn. Brachiaria bryzantha) ou Urochloa ruziziensis (Syn. Brachiaria ruziziensis).

\section{Material e Métodos}

O estudo consistiu de dois experimentos, realizados por dois anos agrícolas (2008/2009 e 2009/2010), em condições de sequeiro, no Município de Botucatu, SP $\left(22^{\circ} 51^{\prime} \mathrm{S}, 48^{\circ} 26^{\prime} \mathrm{W}\right.$ e altitude de $\left.740 \mathrm{~m}\right)$. Em um experimento, a cultura do feijão foi semeada em sucessão ao milho safrinha, consorciado com U. brizantha cv. Marandu e, no outro, após milho safrinha consorciado com U. ruziziensis cv. Comum. A semeadura das forrageiras foi realizada em março, concomitantemente com a cultura do milho safrinha e com a adubação no sulco de semeadura. Ambas as áreas haviam sido manejadas em SPD e cultivadas com a cultura do feijão, por cinco anos, antes dos consórcios de milho com espécies de braquiárias. $\mathrm{Na}$ adubação das culturas de feijão precedentes aos consórcios, foram utilizados $50 \mathrm{~kg} \mathrm{ha}^{-1}$ de $\mathrm{N}$, $45 \mathrm{~kg} \mathrm{ha}^{-1}$ de $\mathrm{P}_{2} \mathrm{O}_{5}$ e $48 \mathrm{~kg} \mathrm{ha}^{-1}$ de $\mathrm{K}_{2} \mathrm{O}$. Na adubação dos consórcios de milho com espécies de braquiária, foram utilizados $60 \mathrm{~kg} \mathrm{ha}^{-1}$ de $\mathrm{N}, 70 \mathrm{~kg} \mathrm{ha}^{-1}$ de $\mathrm{P}_{2} \mathrm{O}_{5}$ e $40 \mathrm{~kg} \mathrm{ha}^{-1}$ de $\mathrm{K}_{2} \mathrm{O}$.

O solo da área experimental é classificado como Latossolo Vermelho distroférrico. Em cada ano agrícola, antes da instalação dos experimentos, foi realizada a amostragem de solo, na camada de 0-20 cm, para a determinação das características químicas. Na área utilizada em 2008/2009, o solo tinha a seguinte composição: matéria orgânica, $34,2 \mathrm{~g} \mathrm{dm}^{-3}$; $\mathrm{pH}\left(0,01 \mathrm{~mol} \mathrm{~L}^{-1} \mathrm{CaCl}_{2}\right), 5,0 ; \mathrm{P}$ (resina), $11 \mathrm{mg} \mathrm{dm}^{-3}$; $\mathrm{K}, \mathrm{Ca}, \mathrm{Mg}$ e $\mathrm{H}+\mathrm{Al}, 1,4,33,14$ e $45 \mathrm{mmol}_{\mathrm{c}} \mathrm{dm}^{-3}$, respectivamente; e $\mathrm{V}, 53 \%$. $\mathrm{Na}$ área utilizada em 2009/2010, a composição do solo era a seguinte: matéria orgânica, 33,5 $\mathrm{g} \mathrm{dm}^{-3} ; \mathrm{pH}\left(0,01 \mathrm{~mol} \mathrm{~L}^{-1} \mathrm{CaCl}_{2}\right)$, 5,4; P (resina), $12 \mathrm{mg} \mathrm{dm}^{-3} ; \mathrm{K}, \mathrm{Ca}, \mathrm{Mg}$ e $\mathrm{H}+\mathrm{Al}, 2,4$, 76,22 e $41 \mathrm{mmol}_{\mathrm{c}} \mathrm{dm}^{-3}$, respectivamente; e V, 70\%.

Segundo a classificação climática de Köeppen, o clima predominante na região é do tipo Cwa, caracterizado como clima tropical de altitude, com inverno seco e verão quente e chuvoso. Os dados meteorológicos, registrados durante o período de condução do experimento, encontram-se na Figura 1.

Em cada experimento, foi utilizado o delineamento de blocos ao acaso, em parcelas subdivididas, com quatro repetições. As parcelas foram constituídas pela inoculação ou não de $R$. tropici nas sementes (400 g por $100 \mathrm{~kg}$ de sementes). Foi utilizado o inoculante turfoso (estirpe SEMIA 4080), com $2 \times 10^{9}$ células viáveis por grama (Mastrefix, Stoller, Campinas, SP, 
Brasil). As subparcelas foram constituídas por quatro doses de $\mathrm{N}$ em cobertura $\left(0,35,70\right.$ e $\left.140 \mathrm{~kg} \mathrm{ha}^{-1}\right)$, com uso de nitrato de amônio. Cada unidade experimental tinha dimensão de $2,7 \times 7 \mathrm{~m}$, tendo-se considerado a área central para as avaliações e desprezado $0,5 \mathrm{~m}$ nas extremidades, o que totalizou $10,8 \mathrm{~m}^{2}$ de parcela útil.

Um dia antes da dessecação das plantas presentes nas áreas, foram realizadas coletas do material vegetal. $\mathrm{O}$ material coletado foi seco em estufa a $65^{\circ} \mathrm{C}$ e, em seguida, foram realizadas a pesagem e a transformação dos dados em quilogramas por hectare de matéria seca. O material foi moído para determinação do teor de N (Malavolta et al., 1997), e foi feito o cálculo da quantidade de $\mathrm{N}$, expressa em quilogramas por hectare.

O manejo químico da área foi realizado nos dias 26/11/2008 e 5/1/2010, com o herbicida glifosato (1.981 $\mathrm{g} \mathrm{ha}^{-1}$ do i.a.). Em 2010, oito dias após o manejo foi aplicado o herbicida dicloreto de paraquat (300 $\mathrm{g} \mathrm{ha}^{-1}$ do i.a.).

O feijão, cultivar IAC Alvorada, foi semeado mecanicamente em 16/12/2008 e 9/2/2010, no
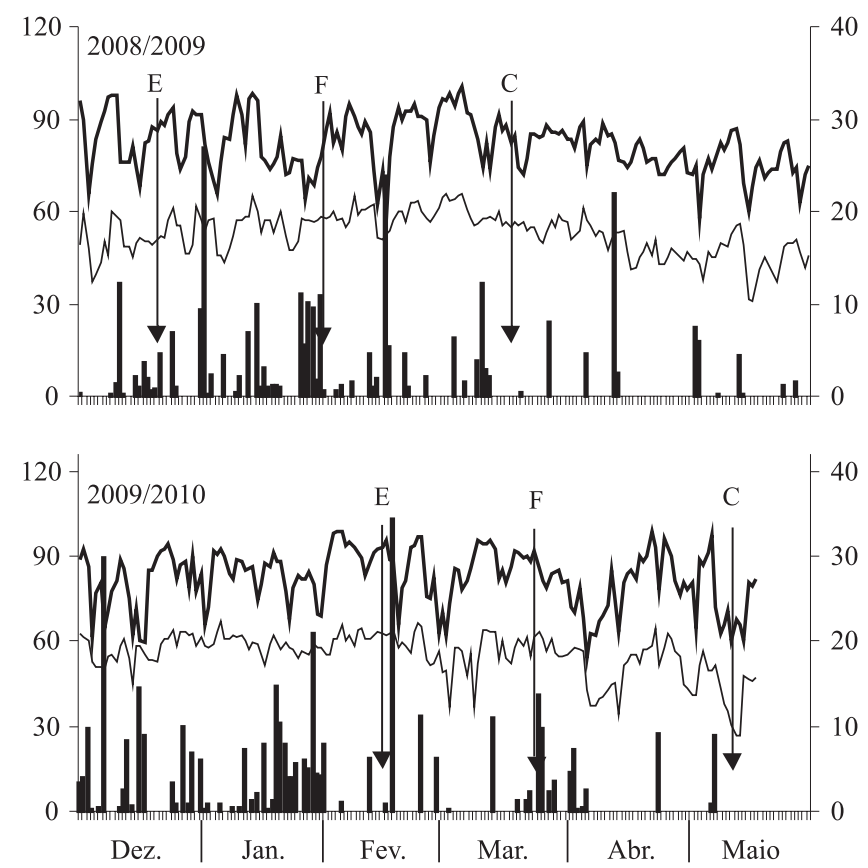

Figura 1. Precipitação pluvial (| ), temperatura máxima $(\rightarrow)$ e temperatura mínima $(-$ ) obtidas na área experimental, de dezembro a maio, nos anos agrícolas de 2008/2009 e 2009/2010, e datas de emergência (E), florescimento (F) e colheita (C) da cultura do feijão. espaçamento de $0,45 \mathrm{~m}$, com 16 sementes por metro de sulco. Em todos os tratamentos, as sementes foram tratadas com o fungicida carbendazim + tiram (45 $+105 \mathrm{~g}$ do i.a. por $100 \mathrm{~kg}$ de sementes), inseticida tiametoxam (105 g do i.a. por $100 \mathrm{~kg}$ de sementes), e cobalto + molibdênio $(3+30 \mathrm{~g}$ por $100 \mathrm{~kg}$ de sementes $)$. Nos tratamentos com inoculação de rizóbio, a mistura do inoculante às sementes foi realizada à sombra, imediatamente antes da semeadura. Nos dois anos agrícolas, a emergência das plântulas ocorreu aos seis dias após a semeadura.

A adubação básica foi de $60 \mathrm{~kg} \mathrm{ha}^{-1}$ de $\mathrm{P}_{2} \mathrm{O}_{5}$ e $40 \mathrm{~kg} \mathrm{ha}^{-1}$ de $\mathrm{K}_{2} \mathrm{O}$, nos dois anos agrícolas. No cálculo da quantidade de fertilizante, foram consideradas as características químicas do solo, a produtividade esperada e as recomendações de Ambrosano et al. (1996). Metade das doses de $\mathrm{N}$ foi aplicada dois dias após a semeadura, e metade quando as plantas apresentavam três folhas totalmente expandidas, 25 dias após a emergência (DAE). Durante o desenvolvimento da cultura, foram realizados os tratos fitossanitários recomendados.

Por ocasião do florescimento pleno, foram coletados os sistemas radiculares de dez plantas por unidade experimental. Esse material foi lavado e posteriormente, foram determinados o número de nódulos por planta, mediante contagem, e a massa de matéria seca de nódulos, após secagem do material em estufa a $65^{\circ} \mathrm{C}$, e pesagem. Para a determinação de $\mathrm{N}$ na folha, foi amostrada, em dez plantas por unidade experimental, a terceira folha com pecíolo (Ambrosano et al., 1996). $\mathrm{O}$ material foi seco em estufa a $65^{\circ} \mathrm{C}$ e, em seguida, as plantas foram moídas para posterior determinação do teor de N (Malavolta et al., 1997).

A massa de matéria seca da parte aérea foi determinada por meio da coleta de dez plantas por unidade experimental, que foram secas em estufa a $65^{\circ} \mathrm{C}$ e pesadas. Após pesagem, as plantas foram moídas e analisadas quanto ao teor de $\mathrm{N}$ (Malavolta et al., 1997). Com esses resultados, foram estimadas as quantidades de $\mathrm{N}$ absorvidas por área, mediante a contagem do número de plantas, em $5 \mathrm{~m}$ de duas linhas da área útil de cada unidade experimental.

Porocasião da colheita do feijão, foram determinados: a população final de plantas, o número de vagens por planta e a produtividade de grãos. As plantas contidas em duas linhas de $5 \mathrm{~m}$ de comprimento, na área útil de cada unidade experimental, foram colhidas 
manualmente. Após a trilha mecânica e a limpeza, os grãos foram pesados e, posteriormente, foi calculada a produtividade de grãos em quilogramas por hectare, a $13 \%$ de umidade (base úmida).

Os dados obtidos foram submetidos à análise de variância. As médias dos tratamentos de inoculação foram comparadas pelo teste $\mathrm{t}$ (DMS), a $5 \%$ de probabilidade, e os efeitos das doses de $\mathrm{N}$ foram avaliados por meio de análise de regressão, tendose utilizado como critério para escolha do modelo, a magnitude dos coeficientes de regressão, significativos a $5 \%$ de probabilidade pelo teste t. Foi utilizado o Sisvar, versão 4.3 (Ferreira, 2008) para as análises estatísticas.

\section{Resultados e Discussão}

O consórcio de milho com $U$. brizantha, no período da safrinha, proporcionou acúmulos de massa de matéria seca, na época do manejo químico, de 15,4 e 16,5 $\mathrm{Mg} \mathrm{ha}^{-1}$, nos anos agrícolas de 2008/2009 e 2009/2010, respectivamente. $\mathrm{O}$ consórcio milho e $U$. ruziziensis proporcionou 13,7 e 16,4 $\mathrm{Mg} \mathrm{ha}^{-1}$ de massa de matéria seca, respectivamente, nos anos agrícolas de 2008/2009 e 2009/2010. Ambos os consórcios proporcionaram boa cobertura do solo durante todo o ciclo do feijoeiro. Aidar et al. (2000), na safra de verão, constataram que a palhada de $U$. brizantha, associada aos restos da cultura do milho, apresentou massa de matéria seca de $16 \mathrm{Mg} \mathrm{ha}^{-1}$, quantidade suficiente para a proteção plena do solo por mais de 107 dias (ciclo do feijão). Vale destacar que, no presente trabalho, o consórcio foi estabelecido em condições de safrinha (março/ abril).

As quantidades de $\mathrm{N}$, acumuladas na biomassa, foram de 155,8 e 168,4 $\mathrm{kg} \mathrm{ha}^{-1}$, no consórcio milho e $U$. brizantha, e de 148,2 e $145,4 \mathrm{~kg} \mathrm{ha}^{-1}$ no consórcio milho e $U$. ruziziensis, respectivamente, nos anos agrícolas de 2008/2009 e 2009/2010. Binotti (2009) verificou acúmulo médio de $109,5 \mathrm{~kg} \mathrm{ha}^{-1}$ de $\mathrm{N}$ na biomassa de $U$. brizantha associada ao milho, na safra de verão.

Houve presença de nódulos no sistema radicular do feijoeiro, tanto em plantas originadas de sementes com inoculação quanto nas originadas de sementes sem inoculação, independentemente da cultura antecessora e em ambos os anos agrícolas (Tabela 1). A inoculação de rizóbio não interferiu no número e nem na massa de matéria seca de nódulos. Segundo Silva et al. (2009) e Kaneko et al. (2010), a ocorrência de nódulos no feijoeiro-comum que não recebeu inoculação indica a presença de estirpes nativas no solo, capazes de fixar $\mathrm{N}_{2}$ simbioticamente, mas que limitam o estabelecimento das estirpes inoculadas, que são mais eficientes. Não

Tabela 1. Número de nódulos por planta, matéria seca de nódulos e teor de $\mathrm{N}$ na folha, em função da inoculação com rizóbio e da adubação nitrogenada, na cultura do feijão, em sucessão ao milho safrinha consorciado com Urochloa brizantha e Urochloa ruziziensis, no sistema plantio direto ${ }^{(1)}$.

\begin{tabular}{|c|c|c|c|c|c|c|c|c|c|c|c|c|}
\hline \multirow[t]{2}{*}{ Consórcio } & \multirow[t]{2}{*}{ Ano } & \multicolumn{2}{|c|}{ Inoculação (I) } & \multirow{2}{*}{$\begin{array}{l}\mathrm{CV} \\
(\%)\end{array}$} & \multicolumn{4}{|c|}{ Adubação nitrogenada $\left(\mathrm{kg} \mathrm{ha}^{-1}\right)(\mathrm{N})$} & \multirow{2}{*}{$\begin{array}{l}\mathrm{CV} \\
(\%)\end{array}$} & \multirow{2}{*}{$\begin{array}{c}\text { Interação } \\
\text { IxN }\end{array}$} & \multirow[t]{2}{*}{ Equação de regressão } & \multirow[t]{2}{*}{$\mathrm{R}^{2}$} \\
\hline & & Sem & Com & & 0 & 35 & 70 & 140 & & & & \\
\hline & \multicolumn{12}{|c|}{ Número de nódulos por planta } \\
\hline \multirow{2}{*}{$\begin{array}{l}\text { Milho }+ \\
\text { U. brizantha }\end{array}$} & $2008 / 2009$ & $46,3 \mathrm{a}$ & $32,0 \mathrm{a}$ & 56,3 & 40,7 & 57,1 & 31,3 & 27,6 & 48,3 & ns & $\mathrm{y}=48,025-0,1442 * x$ & 0,43 \\
\hline & $2009 / 2010$ & $22,9 \mathrm{a}$ & $16,9 \mathrm{a}$ & 40,9 & 24,6 & 22,8 & 16,3 & 16,2 & 56,8 & ns & ns & - \\
\hline \multirow{3}{*}{$\begin{array}{l}\text { Milho }+ \\
\text { U. ruziziensis }\end{array}$} & $2008 / 2009$ & $25,8 \mathrm{a}$ & $28,3 a$ & 35,6 & 38,7 & 29,6 & 23,6 & 16,5 & 34,3 & ns & $\mathrm{y}=36,455-0,1529 * x$ & 0,94 \\
\hline & $2009 / 2010$ & $15,2 \mathrm{a}$ & $16,2 \mathrm{a}$ & 22,1 & 15,9 & 19,8 & 16,2 & 11,0 & 32,5 & & ns & - \\
\hline & \multicolumn{12}{|c|}{ Matéria seca de nódulos (g planta $\left.{ }^{-1}\right)$} \\
\hline \multirow{2}{*}{$\begin{array}{l}\text { Milho }+ \\
\text { U. brizantha }\end{array}$} & $2008 / 2009$ & $0,070 \mathrm{a}$ & $0,047 \mathrm{a}$ & 43,0 & 0,060 & 0,096 & 0,042 & 0,035 & 50,3 & ns & $\mathrm{y}=0,0758-0,00028 * x$ & 0,39 \\
\hline & $2009 / 2010$ & $0,027 \mathrm{a}$ & $0,024 \mathrm{a}$ & 36,9 & 0,032 & 0,033 & 0,023 & 0,014 & 54,5 & ns & $\mathrm{y}=0,0348-0,000143 * * x$ & 0,93 \\
\hline \multirow{3}{*}{$\begin{array}{l}\text { Milho }+ \\
\text { U. ruziziensis }\end{array}$} & $2008 / 2009$ & $0,047 \mathrm{a}$ & $0,052 \mathrm{a}$ & 44,1 & 0,082 & 0,049 & 0,044 & 0,023 & 38,5 & ns & $\mathrm{y}=0,0736-0,00039 * * x$ & 0,88 \\
\hline & $2009 / 2010$ & $0,029 \mathrm{a}$ & $0,030 \mathrm{a}$ & 17,6 & 0,034 & 0,040 & 0,031 & 0,015 & 38,1 & $\mathrm{~ns}$ & $\mathrm{y}=0,04017+0,000163 * x$ & 0,76 \\
\hline & \multicolumn{12}{|c|}{ Teor de $\mathrm{N}$ na folha $\left(\mathrm{g} \mathrm{kg}^{-1}\right)$} \\
\hline \multirow{2}{*}{$\begin{array}{l}\text { Milho }+ \\
\text { U. brizantha }\end{array}$} & $2008 / 2009$ & $39,1 \mathrm{a}$ & $39,0 \mathrm{a}$ & 8,4 & 36,8 & 37,7 & 39,1 & 42,7 & 6,9 & ns & $\mathrm{y}=36,44+0,0429 * *_{\mathrm{x}}$ & 0,98 \\
\hline & $2009 / 2010$ & $40,0 \mathrm{a}$ & $44,9 \mathrm{~b}$ & 4,4 & 37,8 & 44,5 & 43,6 & 44,1 & 11,3 & ns & $y=38,499+0,1471 * x-0,00078 * x^{2}$ & 0,81 \\
\hline \multirow{2}{*}{$\begin{array}{l}\text { Milho }+ \\
\text { U. ruziziensis }\end{array}$} & $2008 / 2009$ & $37,0 \mathrm{a}$ & $38,7 \mathrm{a}$ & 11,2 & 33,5 & 36,0 & 39,7 & 42,1 & 8,2 & ns & $\mathrm{y}=34,0675+0,062 * * \mathrm{x}$ & 0,94 \\
\hline & $2009 / 2010$ & $38,4 \mathrm{a}$ & $41,0 \mathrm{a}$ & 18,6 & 33,7 & 40,9 & 40,8 & 43,5 & 9,7 & ns & $\mathrm{y}=34,355+0,160 * * x-0,00068 * x^{2}$ & 0,89 \\
\hline
\end{tabular}


houve interação entre a inoculação com rizóbio e a adubação nitrogenada.

Em 2008/2009, verificou-se redução linear do número de nódulos com o aumento da dose de $\mathrm{N}$ aplicada (Tabela 1); já em 2009/2010, não houve efeito significativo da aplicação de $\mathrm{N}$ no número de nódulos por planta. Também houve diminuição da produção de matéria seca de nódulos, com o aumento das doses de $\mathrm{N}$ aplicadas em cobertura, nos dois anos agrícolas. Soares et al. (2006), Pelegrin et al. (2009), Silva et al. (2009), Valadão et al. (2009) e Kaneko et al. (2010) também verificaram que o $\mathrm{N}$ fornecido via adubação reduziu o estabelecimento das bactérias simbiontes e, consequentemente, o número e a produção de matéria seca dos nódulos. Esses resultados comprovam a interferência negativa do $\mathrm{N}$ mineral, fornecido pela adubação, no estabelecimento e reprodução das bactérias fixadoras de $\mathrm{N}_{2}$, no sistema radicular do feijoeiro-comum.

A inoculação de rizóbio nas sementes proporcionou maior teor de $\mathrm{N}$ na folha do feijoeiro apenas no segundo ano agrícola, no experimento realizado em sucessão ao consórcio milho e $U$. brizantha (Tabela 1). Isto indica que a inoculação nas sementes da estirpe de $R$. tropici selecionada pode ter contribuído para fixação de $\mathrm{N}_{2}$ atmosférico pelo feijoeiro, apesar de não ter interferido na nodulação (Tabela 1). Silva et al. (2009) e Kaneko et al. (2010) não observaram influência da inoculação nos teores foliares de N no feijoeiro. Entretanto, Araújo et al. (2007) verificaram maior concentração de $\mathrm{N}$ nas folhas do feijoeiro-comum, no tratamento que recebeu o inoculante, em relação à testemunha sem inoculação e adubação mineral e em comparação ao tratamento sem inoculação com aplicação em cobertura de $45 \mathrm{~kg} \mathrm{ha}^{-1}$ de $\mathrm{N}$ (100 kg de ureia).

Com relação às doses de $\mathrm{N}$, em 2008/2009, houve efeito linear no teor do nutriente nas folhas do feijoeiro cultivado sobre os dois tipos de palhada (Tabela 1). Soratto et al. (2004) também obtiveram, em SPD, efeito linear da adubação nitrogenada de cobertura sobre o teor de N da folha do feijoeiro. Em 2009/2010, a aplicação de $\mathrm{N}$ proporcionou aumentos no teor desse nutriente na folha do feijoeiro, e o efeito foi quadrático, com os maiores valores observados com a dose máxima calculada de $94 \mathrm{~kg} \mathrm{ha}^{-1}$, após o cultivo de milho e $U$. brizantha e de $118 \mathrm{~kg} \mathrm{ha}^{-1}$ após o de milho e U. ruziziensis. Kaneko et al. (2010) também observaram efeito quadrático da adubação nitrogenada no teor de $\mathrm{N}$ da folha do feijoeiro, no segundo ano de cultivo em SPD. Deve-se salientar que em todos os tratamentos os teores de $\mathrm{N}$ foliar estavam dentro da faixa 30-50 $\mathrm{g} \mathrm{kg}^{-1}$, considerada adequada para o feijoeiro (Ambrosano et al., 1996). Esses resultados indicam que, apesar do aumento no teor de $\mathrm{N}$ na folha do feijoeiro, proporcionada pela aplicação desse nutriente, a quantidade tornada disponível pelos resíduos vegetais foi suficiente para proporcionar adequada nutrição do feijoeiro.

A produção de matéria seca e a quantidade de $\mathrm{N}$ acumulada na parte aérea das plantas não foram influenciadas pela inoculação de $R$. tropici nas sementes (Tabela 2). Silva et al. (2009) e Kaneko et al. (2010) constataram presença de estirpes nativas no solo, onde foram conduzidos seus respectivos experimentos, e também não verificaram diferenças significativas na massa de matéria seca da planta com a inoculação de $R$. tropici. Contudo, a aplicação de $\mathrm{N}$ proporcionou incremento na produção de matéria seca e na quantidade de $\mathrm{N}$ acumulada na parte aérea do feijoeiro em todos os experimentos, o que indica que, apesar de o teor de $\mathrm{N}$ nas folhas dos tratamentos sem aplicação de $\mathrm{N}$ mineral estar dentro da faixa considerada adequada, o feijoeiro respondeu à aplicação de $\mathrm{N}$.

A população final de plantas não foi afetada pelos fatores estudados, e foi de 210 mil plantas $\mathrm{ha}^{-1}$, em 2008/2009, e de 260 mil plantas ha $^{-1}$, em 2009/2010.

O número de vagens por planta foi influenciado apenas pela aplicação de $\mathrm{N}$, em ambos os anos agrícolas, quando o feijoeiro foi cultivado em sucessão ao milho e $U$. brizantha, e pela interação inoculação $\mathrm{x}$ adubação nitrogenada, no segundo ano do cultivo sobre essa palhada (Tabela 2). Segundo Silva et al. (2009), os acréscimos de vagens por planta, com o incremento de doses de $\mathrm{N}$ aplicadas em cobertura, podem ocorrer como conseqüência da maior altura de plantas e da maior emissão de ramos reprodutivos. Mediante o desdobramento da interação (Tabela 3), verifica-se que a inoculação de rizóbio nas sementes aumentou o número de vagens por planta, na ausência da aplicação de N. Na ausência de inoculação, a aplicação de N incrementou o número de vagens por planta até a dose máxima calculada de $105 \mathrm{~kg} \mathrm{ha}^{-1}$. Contudo, na presença de inoculação, as doses de $\mathrm{N}$ não tiverem efeito nos valores dessa variável. Isto é uma indicação de que, no segundo ano, as estirpes utilizadas no tratamento com inoculação foram mais eficientes e podem ter 
contribuído com o suprimento de $\mathrm{N}$ para o feijoeiro, quando esse elemento não foi aplicado via adubação.

A produtividade de grãos do feijoeiro não foi alterada pela inoculação de $R$. tropici (Tabela 4). Resultados semelhantes foram obtidos por Binotti (2009), Silva et al. (2009) e Kaneko et al. (2010), que não verificaram efeito da inoculação de rizóbio nas sementes na produtividade do feijoeiro.
A produtividade de grãos aumentou de forma quadrática, com o acréscimo das doses de $\mathrm{N}$ aplicadas, até a dose máxima calculada de $98 \mathrm{~kg} \mathrm{ha}^{-1}$, porém apenas no segundo ano agrícola e quando o feijão foi cultivado após o consórcio milho e $U$. brizantha (Tabela 4). Silva et al. (2009) não detectaram diferença significativa, com o incremento das doses de $\mathrm{N}$ utilizadas para adubação nitrogenada em cobertura no

Tabela 2. Matéria seca da parte aérea, $\mathrm{N}$ acumulado na parte aérea e número de vagens por planta, em função da inoculação com rizóbio e da adubação nitrogenada, na cultura do feijão, em sucessão ao milho safrinha consorciado com Urochloa brizantha e Urochloa ruziziensis, no sistema plantio direto ${ }^{(1)}$.

\begin{tabular}{|c|c|c|c|c|c|c|c|c|c|c|c|c|}
\hline \multirow[t]{2}{*}{ Consórcio } & \multirow[t]{2}{*}{ Ano } & \multicolumn{2}{|c|}{ Inoculação (I) } & \multirow{2}{*}{$\begin{array}{l}\mathrm{CV} \\
(\%) \\
\end{array}$} & \multicolumn{4}{|c|}{ Adubação nitrogenada $\left(\mathrm{kg} \mathrm{ha}^{-1}\right)(\mathrm{N})$} & \multirow{2}{*}{$\begin{array}{l}\text { CV } \\
(\%)\end{array}$} & \multirow{2}{*}{$\begin{array}{c}\text { Interação } \\
\text { IxN }\end{array}$} & \multirow[t]{2}{*}{ Equação de regressão } & \multirow[t]{2}{*}{$\mathrm{R}^{2}$} \\
\hline & & Sem & Com & & 0 & 35 & 70 & 140 & & & & \\
\hline & \multicolumn{12}{|c|}{ Matéria seca da parte aérea (g por planta) } \\
\hline \multirow{2}{*}{$\begin{array}{l}\text { Milho + } \\
\text { U. brizantha }\end{array}$} & $2008 / 2009$ & $11,8 \mathrm{a}$ & $11,7 \mathrm{a}$ & 11,6 & 8,5 & 10,5 & 13,8 & 14,3 & 15,9 & ns & $y=8,249+0,0991 * * x-0,0004 * x^{2}$ & 0,95 \\
\hline & $2009 / 2010$ & $6,5 \mathrm{a}$ & $7,1 \mathrm{a}$ & 23,1 & 4,7 & 6,7 & 7,2 & 8,7 & 17,8 & ns & $y=5,2017+0,266^{* * x}$ & 0,93 \\
\hline \multirow{3}{*}{$\begin{array}{l}\text { Milho }+ \\
\text { U. ruziziensis }\end{array}$} & $2008 / 2009$ & $12,7 \mathrm{a}$ & $11,6 \mathrm{a}$ & 17,0 & 8,3 & 12,1 & 13,9 & 14,5 & 19,9 & ns & $\mathrm{y}=8,3496+0,12023 * x-0,00054 * x^{2}$ & 0,99 \\
\hline & $2009 / 2010$ & $6,9 \mathrm{a}$ & $6,4 \mathrm{a}$ & 14,5 & 4,9 & 6,7 & 6,9 & 8,0 & 22,0 & ns & $y=5,437+0,0197 * * x$ & 0,87 \\
\hline & \multicolumn{12}{|c|}{$\mathrm{N}$ acumulado na parte aérea $\left(\mathrm{kg} \mathrm{ha}^{-1}\right)$} \\
\hline \multirow{2}{*}{$\begin{array}{l}\text { Milho }+ \\
\text { U. brizantha }\end{array}$} & $2008 / 2009$ & $64,8 \mathrm{a}$ & $72,0 \mathrm{a}$ & 18,5 & 43,1 & 61,9 & 86,3 & 82,2 & 21,6 & ns & $\mathrm{y}=41,289+0,882 * * x-0,0042 * * x^{2}$ & 0,96 \\
\hline & $2009 / 2010$ & $55,9 \mathrm{a}$ & $57,8 \mathrm{a}$ & 33,8 & 39,8 & 57,7 & 55,0 & 78,3 & 26,9 & ns & $\mathrm{y}=42,309+0,2515^{* *} \mathrm{x}$ & 0,90 \\
\hline \multirow{3}{*}{$\begin{array}{l}\text { Milho + } \\
\text { U. ruziziensis }\end{array}$} & $2008 / 2009$ & $66,7 \mathrm{a}$ & $59,1 \mathrm{a}$ & 34,1 & 37,3 & 56,5 & 76,3 & 81,6 & 29,6 & ns & $y=36,314+0,7598 * * x-0,0031 * x^{2}$ & 0,99 \\
\hline & $2009 / 2010$ & $59,4 \mathrm{a}$ & $57,0 \mathrm{a}$ & 19,3 & 40,4 & 59,1 & 62,7 & 70,7 & 29,7 & ns & $\mathrm{y}=46,288+0,195 * * x$ & 0,82 \\
\hline & \multicolumn{12}{|c|}{ № de vagens por planta } \\
\hline \multirow{2}{*}{$\begin{array}{l}\text { Milho + } \\
\text { U. brizantha }\end{array}$} & $2008 / 2009$ & $6,5 \mathrm{a}$ & $6,9 \mathrm{a}$ & 25,0 & 5,4 & 6,7 & 6,6 & 8,1 & 20,1 & ns & $y=5,615+0,018^{* *} x$ & 0,92 \\
\hline & $2009 / 2010$ & $7,5 \mathrm{a}$ & $8,3 \mathrm{a}$ & 16,6 & 6,9 & 8,0 & 7,9 & 8,6 & 15,4 & $*$ & $y=7,242+0,0105^{*} x$ & 0,81 \\
\hline \multirow{2}{*}{$\begin{array}{l}\text { Milho + } \\
\text { U. ruziziensis }\end{array}$} & $2008 / 2009$ & $5,8 \mathrm{a}$ & $5,0 \mathrm{a}$ & 14,4 & 5,3 & 5,4 & 5,1 & 5,8 & 20,1 & ns & ns & - \\
\hline & $2009 / 2010$ & $7,8 \mathrm{a}$ & $6,9 \mathrm{a}$ & 11,6 & 7,4 & 8,2 & 6,7 & 7,2 & 19,6 & ns & ns & - \\
\hline
\end{tabular}

${ }^{(1)}$ Médias seguidas de letras iguais, nas linhas, para o fator inoculação, não diferem entre si pelo teste t (DMS), a 5\% de probabilidade ns Não significativo. $*$ e **Significativo a 5 e $1 \%$ de probabilidade pelo teste $\mathrm{t}$, respectivamente.

Tabela 3. Desdobramento da interação significativa entre inoculação com rizóbio e adubação nitrogenada, para número de vagens por planta, na cultura do feijão em sucessão ao milho safrinha consorciado com Urochloa brizantha, no ano agrícola $2009 / 2010^{(1)}$.

\begin{tabular}{|c|c|c|c|c|c|c|}
\hline \multirow[t]{2}{*}{ Inoculação } & \multicolumn{4}{|c|}{ Adubação nitrogenada $\left(\mathrm{kg} \mathrm{ha}^{-1}\right)$} & \multirow[t]{2}{*}{ Equação de regressão } & \multirow[t]{2}{*}{$\mathrm{R}^{2}$} \\
\hline & 0 & 35 & 70 & 140 & & \\
\hline Sem & $5,7 \mathrm{~b}$ & $8,0 \mathrm{a}$ & $8,3 a$ & $8,0 \mathrm{a}$ & $\mathrm{y}=5,858+0,063 * x-0,0003 * x^{2}$ & 0,95 \\
\hline Com & $8,2 \mathrm{a}$ & $8,1 \mathrm{a}$ & $7,5 \mathrm{a}$ & $9,3 \mathrm{a}$ & ns & - \\
\hline
\end{tabular}

${ }^{(1)}$ Médias seguidas de letras iguais, nas colunas, não diferem entre si pelo teste $\mathrm{t}(\mathrm{DMS})$, a $5 \%$ de probabilidade. ${ }^{\text {ns Não }}$ significativo. $*$ e $* *$ Significativo a 5 e $1 \%$ de probabilidade pelo teste $\mathrm{t}$, respectivamente.

Tabela 4. Produtividade de grãos, em função da inoculação (I) com rizóbio e da adubação nitrogenada (N) na cultura do feijão, em sucessão ao milho safrinha consorciado com Urochloa brizantha e Urochloa ruziziensis, no sistema plantio direto ${ }^{(1)}$.

\begin{tabular}{|c|c|c|c|c|c|c|c|c|c|c|c|c|}
\hline \multirow[t]{2}{*}{ Consórcio } & \multirow[t]{2}{*}{ Ano } & \multicolumn{2}{|c|}{ Inoculação } & \multirow{2}{*}{$\begin{array}{l}\mathrm{CV} \\
(\%)\end{array}$} & \multicolumn{4}{|c|}{ Adubação nitrogenada $\left(\mathrm{kg} \mathrm{ha}^{-1}\right)$} & \multirow{2}{*}{$\begin{array}{l}\mathrm{CV} \\
(\%)\end{array}$} & \multirow{2}{*}{$\begin{array}{c}\text { Interação } \\
\text { I x N }\end{array}$} & \multirow[t]{2}{*}{ Equação de regressão } & \multirow[t]{2}{*}{$\mathrm{R}^{2}$} \\
\hline & & Sem & Com & & 0 & 35 & 70 & 140 & & & & \\
\hline \multirow{2}{*}{$\begin{array}{l}\text { Milho }+ \\
\text { U. brizantha }\end{array}$} & $2008 / 2009$ & $1.136 \mathrm{a}$ & $1.208 \mathrm{a}$ & 26,4 & 1.118 & 1.159 & 1.196 & 1.215 & 22,8 & ns & ns & - \\
\hline & $2009 / 2010$ & $2.053 \mathrm{a}$ & $1.884 \mathrm{a}$ & 16,1 & 1.804 & 1.937 & 2.096 & 2.036 & 7,9 & ns & $y=1791,66+6,2085^{* *} x-0,0317 * x^{2}$ & 0,96 \\
\hline \multirow{2}{*}{$\begin{array}{l}\text { Milho }+ \\
\text { U. ruziziensis }\end{array}$} & $2008 / 2009$ & $1.084 \mathrm{a}$ & $1.043 \mathrm{a}$ & 16,9 & 1.069 & 1.055 & 1.067 & 1.062 & 25,8 & ns & ns & - \\
\hline & $2009 / 2010$ & $1.798 \mathrm{a}$ & $1.767 \mathrm{a}$ & 7,5 & 1.699 & 1.773 & 1.815 & 1.843 & 10,4 & ns & ns & - \\
\hline
\end{tabular}

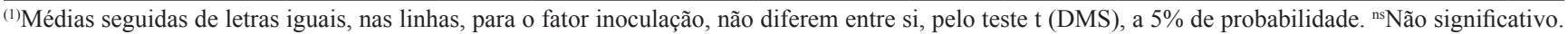
* e**Significativo a 5 e $1 \%$ de probabilidade pelo teste $t$, respectivamente. 
feijoeiro-comum, cultivar IAPAR 81, semeado em SPD após soja ou milho. Silva et al. (2009) não verificaram efeito da adubação nitrogenada na produtividade do feijoeiro em sucessão à soja e milho, no SPD. Soratto et al. (2004) obtiveram efeito quadrático na produtividade de grãos de feijão cultivado em SPD, resultante da aplicação de $\mathrm{N}$ em cobertura, no entanto, a produtividade máxima foi alcançada com a dose estimada de $182 \mathrm{~kg} \mathrm{ha}^{-1}$ de $\mathrm{N}$, ou seja, bem acima da maior dose utilizada no presente trabalho. Soratto et al. (2006) e Crusciol et al. (2007) também verificaram aumento da produtividade do feijoeiro cultivado em SPD, com a aplicação de N em cobertura. Segundo Pelegrin et al. (2009), a variabilidade nas respostas do feijoeiro às doses de $\mathrm{N}$, nos diferentes experimentos, tem sido verificada especialmente em razão dos níveis de fertilidade do solo e de outras técnicas empregadas nos sistemas produtivos, em que se destaca o uso de sistemas de irrigação.

A menor produtividade de grãos observada no ano agrícola de 2008/2009, independentemente do tratamento utilizado, mesmo com melhores condições climáticas para o desenvolvimento das plantas (Figura 1), está relacionada à elevada infestação da cultura pela lagarta falsa-medideira (Pseudoplusia includens), durante as fases de formação das vagens e enchimento de grãos. Provavelmente a ocorrência do inseto também foi o motivo para a ausência de efeito dos tratamentos, especialmente da aplicação de N, na produtividade de grãos do feijoeiro, no primeiro ano, já que foram observados efeitos positivos no teor e no acúmulo de $\mathrm{N}$ nas plantas e matéria seca da parte aérea (Tabelas 1 e 2).

Além disso, nos dois experimentos, a pequena resposta ou a ausência dessa à adubação nitrogenada, quanto à produtividade de grãos de feijoeiro cultivado no SPD e com grande aporte de palhada de braquiária, pode estar relacionada ao fornecimento de $\mathrm{N}$ pela fixação simbiótica de estirpes nativas do solo e, principalmente, à liberação de $\mathrm{N}$ dos resíduos vegetais. Crusciol et al. (2009), na mesma região do presente trabalho, observaram aos 34 dias após o manejo, que aproximadamente $47 \%$ do $\mathrm{N}$ contido na palhada da $U$. brizantha $c v$. Marandu já havia sido liberado e podia ser utilizado pela cultura em sucessão, enquanto $72 \%$ da palhada ainda persistia na superfície do solo.

\section{Conclusões}

1. O feijoeiro cultivado em sucessão ao milho safrinha consorciado com espécies de braquiária, no SPD, não é influenciado pela inoculação de Rhizobium tropici nas sementes.

2. O acréscimo das doses de $\mathrm{N}$ em cobertura diminui o número e a produção de matéria seca dos nódulos e aumenta a produção de matéria seca, o teor e o acúmulo de $\mathrm{N}$ na parte aérea do feijoeiro.

3. A produtividade de grãos do feijoeiro é pouco influenciada pela adubação nitrogenada.

\section{Agradecimentos}

Ao Conselho Nacional de Desenvolvimento Científico e Tecnológico, por concessão de bolsa.

\section{Referências}

AIDAR, H.; THUNG, M.; OLIVEIRA, I.P. de; KLUTHCOUSKI, J.; CARNEIRO, G.E.S.; SILVA, J.G.; DEL PELOSO, M.J. Bean production and white mould incidence under no-till system. Annual Report of the Bean Improvement Cooperative, v.43, p.150-151, 2000 .

AMBROSANO, E.J.; TANAKA, R.T.; MASCARENHAS, H.A.A.; RAIJ, B. van; QUAGGIO, J.A.; CANTARELLA, H. Leguminosas e oleaginosas. In: RAIJ, B. van; CANTARELLA, H.; QUAGGIO, J.A.; FURLANI, A.M.C. (Ed.). Recomendações de adubação e calagem para o Estado de São Paulo. 2.ed. Campinas: Instituto Agronômico, 1996. p.189-203. (IAC. Boletim técnico, 100).

ARAÚJO, F.F. de; CARMONA, F.G.; TIRITAN, C.S.; CRESTE, E. Fixação biológica de $\mathrm{N}_{2}$ no feijoeiro submetido a dosagens de inoculante e tratamento químico na semente comparado à adubação nitrogenada. Acta Scientiarum. Agronomy, v.29, p.540-540. 2007.

BARROTI, G.; NAHAS, E. População microbiana total e solubilizadora de fosfato em solo submetido a diferentes sistemas de cultivo. Pesquisa Agropecuária Brasileira, v.35, p.2043-2050, 2000.

BINOTTI, F.F. da S. Manejo do nitrogênio no feijoeiro de inverno em sucessão a milho e Brachiaria em sistema de plantio direto. 2009. 178p. Tese (Doutorado) - Universidade Estadual Paulista, Ilha Solteira.

BOER, C.A.; ASSIS, R.L. de; SILVA, G.P.; BRAZ, A.J.B.P.; BARROSO, A.L. de L.; CARGNELUTTI FILHO, A.; PIRES, F.R. Ciclagem de nutrientes por plantas de cobertura na entressafra em um solo de Cerrado. Pesquisa Agropecuária Brasileira, v.42, p.1269-1276, 2007.

CECCON, G.; MATOSO, A.O.; NETONETO,A.L.; PALOMBO, L. Uso de herbicidas no consórcio de milho safrinha com Brachiaria ruziziensis. Planta Daninha, v.28, p.359-362, 2010. 
CRUSCIOL, C.A.C.; SORATTO, R.P.; BORGHI, E.; MATEUS, G.P. Integração lavoura-pecuária: benefícios das gramíneas perenes nos sistemas de produção. Informações Agronômicas, n.125, p.2-15, 2009.

CRUSCIOL, C.A.C.; SORATTO, R.P.; SILVA. L.M. da; LEMOS, L.B. Fontes e doses de nitrogênio para o feijoeiro em sucessão a gramíneas no sistema plantio direto. Revista Brasileira de Ciência do Solo, v.31, p.1545-1552, 2007.

FERREIRA, D.F. SISVAR: um programa para análises e ensino de estatística. Revista Symposium, v. 6, p.36-41, 2008.

KANEKO, F.H.; ARF, O.; GITTI, D. de C.; ARF, M.V.; FERREIRA, J.P.; BUZETTI, S. Mecanismos de abertura de sulcos, inoculação e adubação nitrogenada em feijoeiro em sistema plantio direto. Bragantia, v.69, p.125-133, 2010.

KLUTHCOUSKI, J.; STONE, L.F. Desempenho de culturas anuais sobre palhada de braquiária. In: KLUTHCOUSKI, J.: STONE, L.F.; AIDAR, H. (Ed.). Integração lavoura-pecuária. Santo Antônio de Goiás: Embrapa Arroz e Feijão, 2003. p.499-522.

MALAVOLTA, E.; VITTI, G.C.; OLIVEIRA, S.A. de. Avaliação do estado nutricional de plantas: princípios e aplicações. Piracicaba: Associação Brasileira para Pesquisa da Potassa e do Fosfato, 1997. 308p.

MARTÍNEZ-ROMERO， E.; SEGOVIA， L.; MERCANTE, F.M.; FRANCO, A.A.; GRAHAM, P.; PARDO, M.A. Rhizobium tropici, a novel species nodulating Phaseolus vulgaris L. beans and Leucaena sp. Trees. International Journal of Systematic Bacteriology, v.41, p.417-426, 1991.

PELEGRIN, R. de; MERCANTE, F.M.; OTSUBO, I.M.N.; OTSUBO, A.A. Resposta da cultura do feijoeiro à adubação nitrogenada e à inoculação com rizóbio. Revista Brasileira de Ciência do Solo, v.33, p. 219-226, 2009.

RAPOSEIRAS, R.; MARRIEL, I.E.; MUZZI, M.R.S.; PAIVA, E.; PEREIRA FILHO, I.A.; CARVALHAIS, L.C.; PASSOS, R.V.M.; PINTO, P.P.; SÁ, N.M.H. de. Rhizobium strains competitiveness on bean nodulation in Cerrado soils. Pesquisa Agropecuária Brasileira, v.41, p.439-447, 2006.

SANTOS, A.B. dos; FAGERIA, N.K.; SILVA, O.F. da; MELO, M.L.B. de. Resposta do feijoeiro ao manejo de nitrogênio em várzeas tropicais. Pesquisa Agropecuária Brasileira, v.38, p.1265-1271, 2003.

SILVA, E.F. da; MARCHETTI, M.E.; SOUZA, L.C.F. de; MERCANTE, F.M.; RODRIGUES, E.T.; VITORINO, A.C.T. Inoculação do feijoeiro com Rhizobium tropici associada a exsudato de Mimosa flocculosa com diferentes doses de nitrogênio. Bragantia, v.68, p.443-451, 2009.

SILVA, M.B. da; KLIEMANN, H.J.; SILVEIRA, P.M. da; LANNA, A.C. Atributos biológicos do solo sob influência da cobertura vegetal e do sistema de manejo. Pesquisa Agropecuária Brasileira, v.42, p.1755-1761, 2007.

SILVEIRA, P.M. da; BRAZ, A.J.B.P.; KLIEMANN, H.J.; ZIMMERMANN, F.J.P. Adubação nitrogenada no feijoeiro cultivado sob plantio direto em sucessão de culturas. Pesquisa Agropecuária Brasileira, v.40, p.377-381, 2005.

SOARES, A.L. de L.; FERREIRA, P.A.A.; PEREIRA, J.P.A.R.; VALE, H.M.M. do; LIMA, A.S.; ANDRADE, M.J.B. de; MOREIRA, M. de S. Eficiência agronômica de rizóbios selecionados e diversidade de populações nativas nodulíferas em Perdões (MG): II - feijoeiro. Revista Brasileira de Ciência Solo, v.30, p.803-811, 2006.

SORATTO, R.P.; CARVALHO, M.A.C. de; ARF, O. Nitrogênio em cobertura no feijoeiro cultivado em plantio direto. Revista Brasileira de Ciência do Solo, v.30, p.259-266, 2006.

SORATTO, R.P.; CARVALHO, M.A.C. de; ARF, O. Teor de clorofila e produtividade do feijoeiro em razão da adubação nitrogenada. Pesquisa Agropecuária Brasileira, v.39, p.895-901, 2004.

VALADÃO, F.C. de A.; JAKELAITIS, A.; CONUS, L.A.; BORCHARTT, L.; OLIVEIRA, A.A. de; VALADÃO JUNIOR, D.D. Inoculação das sementes e adubações nitrogenada e molíbdica do feijoeiro-comum, em Rolim de Moura, RO. Acta Amazônica, v.39, p.741-747, 2009.

VIEIRA, R.F.; TSAI, S.M.; TEIXEIRA, M.A. Nodulação e fixação simbiótica de nitrogênio em feijoeiro com estirpes nativas de rizóbio, em solo tratado com lodo de esgoto. Pesquisa Agropecuária Brasileira, v.40, p.1047-1050, 2005.

Recebido em 6 de dezembro de 2010 e aprovado em 20 de abril de 2011 